Article

\title{
Ozonation of Hot Red Pepper Fruits Increases Their Antioxidant Activity and Changes Some Antioxidant Contents
}

\author{
Monika Sachadyn-Król *®), Małgorzata Materska® and Barbara Chilczuk \\ Department of Chemistry, University of Life Sciences in Lublin, 20-950 Lublin, Poland \\ * Correspondence: monika.sachadyn-krol@up.lublin.pl; Tel.: +48-081-445-65-50
}

Received: 28 June 2019; Accepted: 29 August 2019; Published: 1 September 2019

\begin{abstract}
The effect of treatment of pepper fruits with gaseous ozone and storage time following the ozonation process on changes in the content of lipophilic fraction is analyzed for the first time in this paper. The aim of the present study was to assess the impact of ozone treatment on the composition of lipophilic compound fraction and its antioxidant activity (AA). Pepper fruits of cv. Cyklon were ozonated for 1 and $3 \mathrm{~h}$ immediately after harvesting. Then, the fruits were stored for 30 days under refrigeration conditions. The total content of phenolic compounds and the AA of the lipophilic fraction isolated from the pericarp and placenta of the fruits were investigated after 10, 20, and 30 days of storage. Additionally, quantitative high-performance liquid chromatography diode array detection analysis of individual phenolic compounds was performed. The results revealed that the content and activity of secondary metabolites varied during storage, with the highest values recorded on the 20th day after harvest, both in control and ozonated fruits, regardless of the ozone dosage used. Treatment of the fruits with ozone for $3 \mathrm{~h}$, but not for $1 \mathrm{~h}$, exhibited a positive effect on the phenolic composition and AA during the prolonged storage of pepper fruits. Three hours of ozonation seems to be the appropriate time to increase the persistence of pepper fruits during storage.
\end{abstract}

Keywords: ozone; Capsicum annuum; antioxidants; phenolic compounds

\section{Introduction}

The consumption of raw fruits and vegetables has seen an increasing trend in the last few years due to growing nutritional awareness among the population [1]. In addition, consumer demands for minimally processed foods with natural flavor and taste has led to the development of a number of preservation strategies whose main focus was to extend the shelf life of fruits and vegetables [2]. Fresh or minimally processed fruits and vegetables are highly perishable and easily subjected to post-harvest microbial contaminations and physiological changes during transportation, processing, storage, and wholesale and retail trade [3]. Novel food processing and preservation technologies, while considering microbiological safety, should also ensure, at least, the preservation of ingredients at the same level, or even improvement of, the quality of the raw material [4]. Food manufacturers in association with scientists are looking for methods to extend food shelf life and improve its pro-health properties. The techniques used to achieve this goal are nanoencapsulation or electrospraying [2].

Ozone treatment is being widely used in the food industry, since this procedure involves only minimal postharvest treatments and is relatively inexpensive and available worldwide [5]. Ozone is one of the strongest oxidants exhibiting a broad spectrum of antimicrobial activity-against bacteria, fungi, viruses, protozoa, and also bacterial and fungal spores [6]. The dosage of ozone used in the industry is potent enough to disinfect the surface, which largely eliminates the problem of contamination from mold growth and microbiological infections [1]. Additionally, it also exhibits other positive properties, 
such as decomposition of mycotoxins and the prevention of their recurrence during the storage process [5,7], as well as the ability to degrade pesticide residues present within the food product [8-10]. Despite many studies being published with regard to the beneficial effects associated with the adoption of ozonation process in the food industry, there still exists mistrust among consumers [10]; therefore, the producers do not often inform about using this method. The most commonly used technique in fruit and vegetable processing is storing the raw material in an atmosphere containing low concentrations of ozone [11]. Another approach is subjecting them to a single treatment, but this method requires exposure to higher concentrations of ozone (1-5 ppm for pepper fruits). However, higher dosages of ozone and longer contact time might result in the degradation of fruit quality, owing to increased oxidative stress [12]. Thus, selection and standardization of all the appropriate parameters is of utmost importance. Hence, the ozonation technique is now being comprehensively studied. A number of studies have been conducted to confirm the positive effect of ozone treatment on the shelf life of fruits and vegetables. A few of them were specific to sweet or hot and red or green peppers [12-16]. Most of these studies focus on issues related to the shelf life, like disease development, affecting the microbiological quality; physiological characteristics, resulting in loss of weight, texture, and color; and physicochemical characteristics, concerning ascorbic acid content, physiological and total soluble solids content; or overall acceptability. In the literature, only the works of Glowacz [17,18] and Sachadyn-Król [19] refer to the issue of secondary metabolites in pepper in the context of ozonation.

Red pepper (Capsicum annuum L.) is considered to be a rich source of secondary metabolites, which include compounds with different lipophilicities. Vitamin C, phenolic acids, and their derivatives are hydrophilic compounds, while the dominating acids found in the pepper fruits are gallic and 5-O-caffeoylquinic acid [20]. Compounds that show medium lipophilicity are glycosidic derivatives of flavonoids, mainly quercetin and luteolin, as well as esters of ferulic and sinapic acids [21,22]. Alkaloids, capsaicin, and dihydrocapsaicin, components of hot pepper varieties and various types of capsinoids found in sweet varieties, are lipophilic compounds. The lipophilic fraction also includes terpenoids, which show varying degrees of glycosylation. They are described to be the precursors of carotenoid pigments [22]. Depending on the nature and structure of compounds present in the fruits, the impact following oxidative action of ozone on phenolic compounds may be different. These compounds can block the action of free radicals and are capable of inhibiting the reactions caused by single active atoms of oxygen. Phenolic compounds exhibit antioxidant activity (AA), which is determined by their chemical structure [23]. Previous studies [19] regarding the effect of ozone treatment on the level of secondary metabolites in stored pepper fruits revealed that ozonation for $3 \mathrm{~h}$ induced an increase in the concentration of compounds showing intermediate lipophilicity: quercetin 3-O-rhamnoside and quercetin-3-O-rhamnoside-7-glucoside in fruits stored for 20 days after treatment [19]. These compounds were part of the fraction isolated with $40 \%$ methanol. In the presented work, we focus on a group of lipophilic compounds that are extracted from the pepper extract using $70 \%$ methanol. Since these compounds show affinity for fat, they appear to be potent antioxidants that may show their activity at the level of the cell membrane [23]. The aim of the presented work was to evaluate the impact of ozone treatment on the composition of lipophilic compound fraction and thereby determine its AA.

\section{Materials and Methods}

\subsection{Plant Material and Ozone Treatment}

Fully matured fruits of hot pepper (C. annuum L. var. Cyklon) were analyzed. Plants were cultivated in a greenhouse of the Department of Cultivation and Fertilization of Horticultural Plants, University of Life Sciences, Lublin, Poland. Fully ripe and undamaged fruits (weight: 20-30 g) were selected for the investigation purpose. Fruits were divided into three groups (20 fruits in each) after harvesting, and the first group acted as the control. The other two groups were exposed to a stream of ozone gas at a concentration of $2 \mathrm{mg} / \mathrm{dm}^{3}$ for $1 \mathrm{~h}$ and for $3 \mathrm{~h}$, respectively, at a temperature of $25^{\circ} \mathrm{C}$. 
All experiments were performed in triplicate. The ZY-H103 ozone generator (Zhong-Yi Electronics Co., Ltd, Fujian, China) was used. After ozone treatment, the fruits were stored in the dark at $8{ }^{\circ} \mathrm{C}$ in tightly sealed packages of LDPE film for 10 (T10), 20, (T20), and 30 (T30) days. The control fruits (without treatment) were also stored in similar conditions. For evaluation, the fruits were washed, cut, and pericarps were separated from placenta and analyzed separately. Furthermore, total phenolic content (TPC) and antiradical activity of the selected samples were estimated. In addition, the lipophilic profile of the fraction isolated from placenta and pericarp of pepper fruits was determined by the high-performance liquid chromatography (HPLC) technique.

\subsection{Extraction and Fractionation of Polyphenols}

The protocol followed for extraction and obtaining $70 \%$ methanol fraction is based on our previously published procedure [21]. The pericarp and placentae $(5 \mathrm{~g})$ were homogenized for $15 \mathrm{~min}$ in an $80 \%$ aqueous ethanol solution on a Diax 900 homogenizer (Heidolph, Schwabach, Germany). After filtration on a paper filter, the clear solution was collected and the volume was made up to $50 \mathrm{~mL}$ with $80 \%$ ethanol solution and mixed thoroughly. Then, $40 \mathrm{~mL}$ of ethanolic extract was subjected to solid-phase extraction (SPE) to enable separation of fractions with different lipophilicities. To remove alcohol from the sample, the extracts were evaporated on a rotary vacuum evaporator (Rotavapor R-100, Buchi Labortechnik AG, Flawil, Switzerland) at a temperature of $40^{\circ} \mathrm{C}$. After concentration, $5 \mathrm{~mL}$ of water was added and the diluted samples were applied to SepPak columns ( $2 \mathrm{~g}$, C18; Waters, Milford, CT, USA), which were preconditioned with methanol and water. The portion of extract adsorbed on the SPE column was washed with water and $40 \%$ methanol. After washing, the fraction of lipophilic compounds was eluted using a $70 \%$ aqueous methanol solution. The obtained fractions were evaporated, transferred to tubes of $2 \mathrm{~mL}$ volume, and subjected to further analyses.

\subsection{Determination of the Total Phenolic Content (TPC)}

The TPC was analyzed spectrophotometrically by the Folin-Ciocalteu method [24]. Samples $(60 \mu \mathrm{L})$ diluted with water to a volume of $0.6 \mathrm{~mL}$ were mixed with $\mathrm{Na}_{2} \mathrm{CO}_{3}$ solution $(1.2 \mathrm{~mL}$ at a concentration of $75 \mathrm{~g} / \mathrm{L}$ ), and then Folin's reagent $(1.5 \mathrm{~mL}$ diluted with distilled water at a ratio of 1:10) was added. The prepared mixture was incubated for $30 \mathrm{~min}$ in the dark at room temperature and later the absorbance was measured at a wavelength of $\lambda=750 \mathrm{~nm}$. Spectrophotometric analyses were done using a UV-VIS spectrophotometer (Shimadzu A-160, Shimadzu Corp., Kioto, Japan). Analyses were repeated four times, and the results were presented as means in $\mathrm{mg}$ of chlorogenic acid/100 $\mathrm{g}$ of fresh matter (FM) on the basis of calibration curve prepared for this compound.

\subsection{DPPH Free Radical-Scavenging Assay}

The assessment of antiradical activity of lipophilic fractions extracted from pepper fruits was performed by using synthetic DPPH (1,1-diphenyl-2-picrylhydrazyl) radical assay [25]. In this method, the direct reduction of the DPPH radical is indicated by a change in the color of the reaction mixture. Briefly, $0.1 \mathrm{~mL}$ of the analyzed sample was added to $4 \mathrm{~mL}$ of DPPH solution in $100 \%$ methanol $(0.01 \mathrm{mM})$. In the blank sample, $0.1 \mathrm{~mL}$ of $70 \%$ methanol is added to $4 \mathrm{~mL}$ of methanol DPPH solution. After storing the samples in the shade at room temperature for $30 \mathrm{~min}$, the absorbance was measured at $\lambda=515 \mathrm{~nm}$ with a UV-VIS spectrophotometer.

The AA, expressed as the \% of DPPH radical reduction, was calculated from the formula:

$$
\% \mathrm{AA}=\left[1-\frac{A s}{A b}\right] \times 100 \%
$$

where AA is the antioxidant activity of the analyzed sample, $A s$ is the absorbance of the analyzed sample, and $A b$ is the absorbance of the blank sample. 


\subsection{High-Performance Liquid Chromatography}

Detailed investigations regarding the changes observed in the profile of compounds present in the $70 \%$ fraction, following the ozone treatment and fruit storage, were conducted by HPLC method [21]. The analysis was done on an Empower-Pro chromatograph (Waters, Milford, CT, USA) attached to a quaternary pump (M2998; Waters, Milford, CT, USA), a degasser (In-Line Degasser AF, Waters, Milford, CT, USA), and a UV-VIS diode array detection system (2998 Photodiode Array Detector, Waters, Milford, CT, USA). A column filled with modified silica gel RP-18 (Atlantis T3, $3 \mu \mathrm{m}, 4.6 \mathrm{~mm} \times 150 \mathrm{~mm}$; Waters, Milford, CT, USA) was used. The mobile phase consisted of A (100\% acetonitrile), B $\left(\mathrm{H}_{2} \mathrm{O}\right.$ redistilled), and $\mathrm{C}(100 \%$ methanol) solutions in a proportion in which the concentration of solvents $\mathrm{A}$ and $\mathrm{C}$ (in the same proportion) were as follows: until the $0-15$ th $\mathrm{min}, 18-22 \%$; $15-27 \mathrm{~min}, 22-25 \%$; 27-35 $\mathrm{min}, 25-30 \%$; and 35-45 $\mathrm{min}, 35-50 \%$. The flow speed was $1 \mathrm{~mL} / \mathrm{min}$, and the absorbance was measured at $280 \mathrm{~nm}$. Quantitative analysis was based on the standard calibration curve prepared for quercetin 3-O-rhamnoside, and the concentration of the compounds present in $70 \%$ fraction extracted from the pericarp and placenta was expressed as equivalent of this compound (mg/100 $\mathrm{g}$ of FM).

\subsection{Statistical Analysis}

All analyses were carried out in four replicates, and standard deviations were calculated for each data series as an indicator of dataset scatter plots. To analyze the results obtained for the effect of time of storage, portion of fruit, and ozone treatment on the TPC and antiradical activity, a one-way analysis of variance (ANOVA) was used. The significance of the differences between the means was determined using least-squares means multiple-range test with $5 \%$ probability for error. To assess the relationship between the ozone treatment and alterations in the concentrations of compounds, a Pearson's correlation analysis was performed. A $p$-value $<0.01$ was considered to be significant. Principal component analysis (PCA) was also performed. Statistical comparisons were performed using STATGRAPHIC Centurion software, version XVI (Statgraphic Technologies, Inc., Virginia, USA).

\section{Results and Discussion}

\subsection{TPC and Antioxidant Activity}

Total phenolic content and the antiradical activities of the $70 \%$ fraction were dependent on the anatomical part from where the sample was extracted, the storage time, and the ozonation process. The mean value of TPC was found to be $237.5 \mathrm{mg}$ of chlorogenic acid/100 $\mathrm{g}$ of FM, which was much greater for placenta $(358 \mathrm{mg}$ ) than for pericarp $(245 \mathrm{mg})$. Comparable results for total phenolic compounds were previously noted in the fraction that exhibited medium lipophilicity and was eluted with $40 \%$ methanol. The mean value of TPC was found to be $229.3 \mathrm{mg}$ of chlorogenic acid/100 g of FM [15]. The storage time significantly affected the average TPC values. The highest phenolic content was noted after 20 days of storage ( $350 \mathrm{mg}$ of chlorogenic acid/100 $\mathrm{g}$ of FM) and the lowest at 10 days (T10) (237.5 mg of chlorogenic acid/100 $\mathrm{g}$ of FM). The application of ozone for $3 \mathrm{~h}$ caused a significant increase in the content of total phenolic compounds (Figure 1a-c). This applies to both time periods (T10 and T30). A large increase in TPC after ozonation process is particularly observed in the anatomical part of placenta. In the samples undergoing ozone treatment for $1 \mathrm{~h}$, a different effect was observed. Generally, however, this exposure period is not sufficient to achieve the escalation effect.

Similar results were noted for antiradical activity (AA) against DPPH, and the mean AA value was found to be $61 \%$. The storage time had a statistically significant effect on the AA which was found to be highest after 20 days (71\%) and lowest after 10 days of ozonation (51\%). However, longer storage (T30) did not result in a further increase in AA $(60.5 \%)$. Pericarp showed significantly higher activity compared to the placenta ( $67 \%$ and $55 \%$, respectively). The ozonation period also influenced the change in the mean values of antiradical activity. Three-hour exposure to ozone gas caused an increase in the antiradical activity at 10 and 30 days of storage (Figure 2a-c). A significantly large difference can be seen for the placental sample after 30 days. 


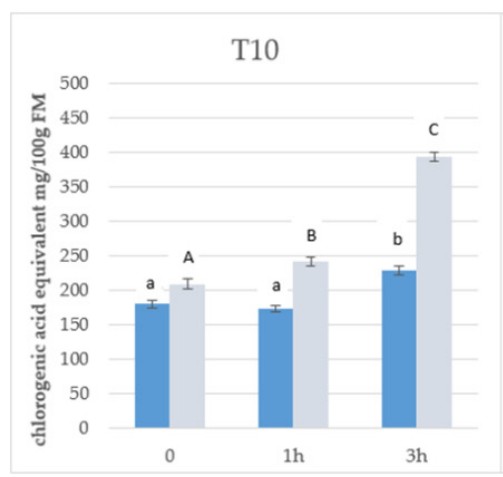

(a)

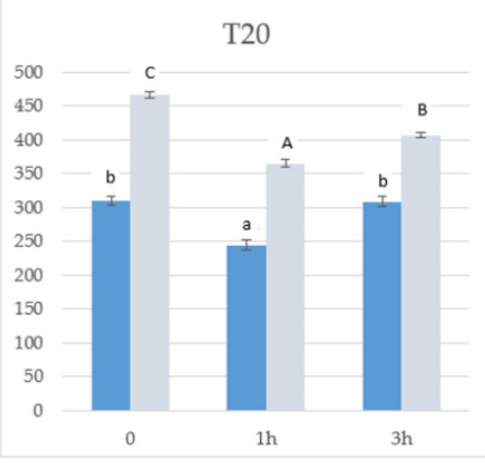

(b)

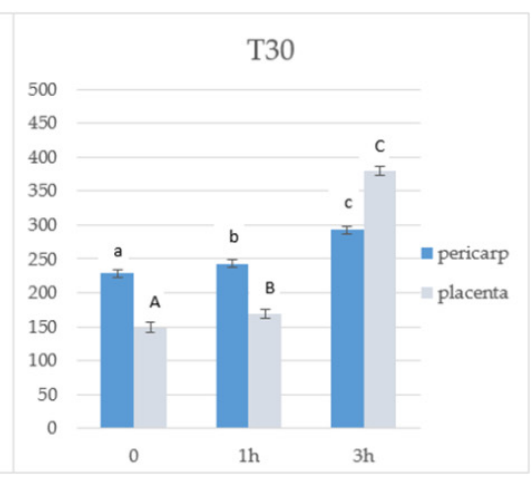

(c)

Figure 1. Total phenolic compounds in the $70 \%$ aqueous methanol fraction obtained from pepper fruits at three lengths of storage: (a) after 10 days (T10), (b) after 20 days (T20), and (c) after 30 days (T30). Notes: ${ }^{1}$ Values in the graphs denoted with the same letters do not differ statistically significantly at $p<0.05 ;^{2}$ Lowercase letters correspond to pericarp and uppercase letters to placenta; FM: fresh matter.

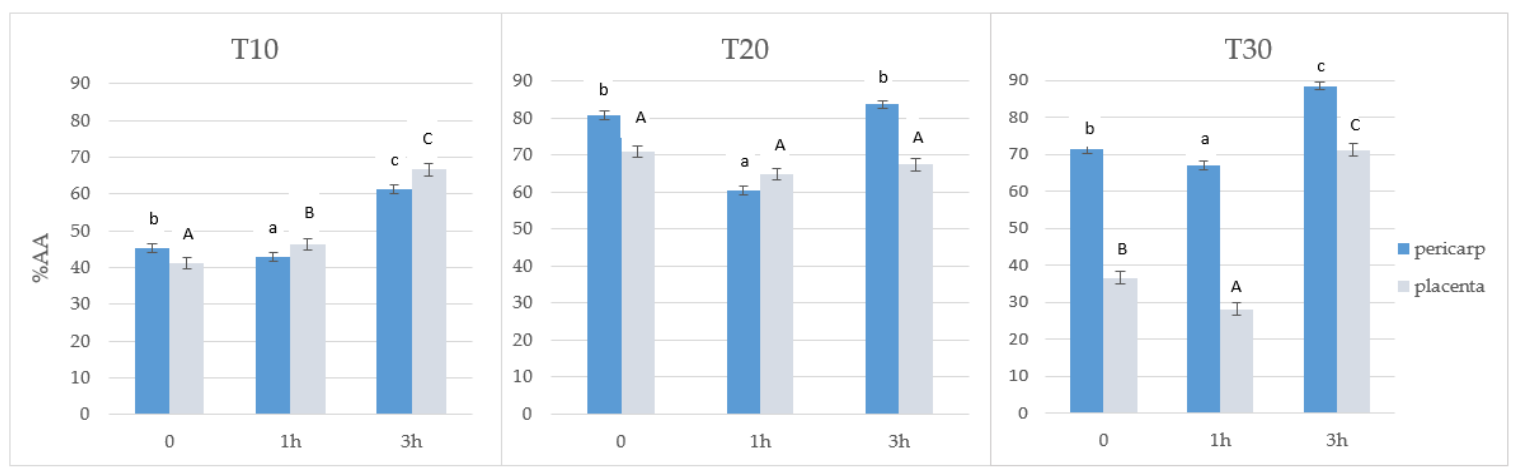

(a)

(b)

(c)

Figure 2. Antiradical activity (\%AA) of the $70 \%$ aqueous methanol fraction obtained from pepper fruits at three lengths of storage: (a) after 10 days (T10), (b) after 20 days (T20), and (c) after 30 days (T30). Notes: ${ }^{1}$ Values in the graphs denoted with the same letters do not differ statistically significantly at $p<0.05 .{ }^{2}$ Lowercase letters correspond to pericarp and uppercase letters to placenta.

The results show higher phenolic content at T20 and T30 for placenta compared to pericarp, but the opposite trend is observed for AA, which was found to be higher for pericarp. This discrepancy may be explained based on the fact that placenta contains some phenolic compounds that possess lipophilic character but do not exhibit AA, e.g., lignin [26,27].

Our findings suggest that the content of phenolic compounds and AA are affected by ozone in a dose-dependent manner. Differences in TPC and AA of 70\% aqueous methanol fraction obtained after 1 and $3 \mathrm{~h}$ of ozone treatment can be explained, similar to the $40 \%$ fraction [19], by the ozonation process itself and its effect on metabolism. When whole fruits were exposed to the ozone gas, the outer portion is mainly exposed to oxidative stress. The shorter ozone treatment $(1 \mathrm{~h})$ resulted in a reduction of the concentration of antioxidants in surface layers due to the occurrence of oxidation process, whereas the concentrations of these compounds in the deeper tissues remained unchanged. In contrast, prolonged exposure of the fruits to ozone gas $(3 \mathrm{~h})$ evoked a stronger system response and probably contributed to the transport of antioxidants from internal tissues to the region of oxidative stress.

The results of our study are consistent with those presented by Glowacz et al. [17]. The TPC was increased in red bell peppers exposed to ozone at $0.1 \mu \mathrm{mol} / \mathrm{mol}$ concentration, while TPC was not affected when these fruits were exposed to higher concentrations of ozone $(0.3 \mu \mathrm{mol} / \mathrm{mol})$. Another work by the same author [18] established that there were no significant differences in terms of TPC in chili peppers. Regardless of ozone concentration, AA was not affected in red chili peppers, but was 
found to be significantly reduced after 14 days in green chili peppers exposed to ozone at $2 \mu \mathrm{mol} / \mathrm{mol}$ concentration when compared with control samples. The authors suggested that green peppers were more sensitive to ozone treatment. However, it is difficult to compare the results of these studies because in that experiment red and green chili peppers were continuously exposed to very low concentrations of ozone during the storage period at $10^{\circ} \mathrm{C}$ for 14 days. In our previous study [19], the highest TPC and antiradical activity were noted in ozone-treated fruits stored for 20 days. On the basis of literature data $[17,19]$ and obtained results, it may be concluded that during the storage period of 20 days, physiological accumulation of secondary metabolites takes place. Storage of fruits for a longer period of time results in degradation of these compounds, and the degraded products serve the role of antioxidants in the cell environment. For this reason, the highest TPC and antiradical activity for control samples was noticed at T20, which rapidly decreased during the next 10 days (Figures 1 and 2). TPC has previously been found to be increased in other ozone-treated fruits and vegetables like bananas and pineapples [28], and papayas [29]. In the study of Ong et al. [29], a significant increase in the TPC of papaya fruits from 4 to 10 days of storage has been noticed. Additionally, antioxidative activity measured by the DPPH and FRAP assays also increased. Rodoni et al. [30] observed changes in these parameters during the storage of ozonated tomato fruit at a temperature of $20^{\circ} \mathrm{C}$. They noted a 50\% increase in the accumulation of total phenolic compounds compared to the control after six days, and a decrease after nine days. However, in this study, no changes in the AA of fruits after ozone treatment were observed. In another experiment [31], the highest antioxidant capacity was found in the methanol extract obtained from ozonated berries. Additionally, ozone-treated raspberries showed a statistically significantly higher level of phenolic compounds and also demonstrated higher total antioxidant capacity as compared to untreated fruits [32]. The impact of ozone on health-promoting, microbiological, and color properties of Rubus ideaus raspberries has also been investigated. More and more attempts are being made to improve the biosynthesis of phenolic compounds and AA of fruits during pre- and postharvest stages [33-35].

Despite many studies, the mechanism behind the increasing concentration of phenolic compounds following ozonation process is not clear. Two probable hypotheses are proposed. One theory states that ozone can lead to the release of some of the bound phenolic compounds through partial demolition of the cell structure [36]. During exposure to ozone gas, modification of the cell wall may occur, which in turn can lead to an increase in the phenolic content of the fruits. These modifications may increase the extraction efficiency and contribute to the release of some conjugated phenolic compounds in the cell wall [28]. In addition, phenolic compounds, depending on their structure, exhibit different tendencies to accumulate within the cell wall [37]. The second theory attributes the increase to the changes in enzymes activities induced by ozone. The rapid accumulation of phenolics can be caused by the activation of preexisting enzymes [30]. This mechanism has also been confirmed by our previous research on pepper fruits [19]. We observed higher activity of guaiacol oxidase and polyphenol oxidase enzymes after ozone treatment.

The results of another study $[1,11]$ demonstrate that ozone treatments with concentrations up to $1 \mu \mathrm{mol} / \mathrm{mol}$ did not show any influence on the content of phenolic compounds and antioxidant activities. Moreover, completely different results have been published by de Souza et al. [38]. A color reduction was observed in sugarcane juice by removal of phenolics. However, this was the goal of the work and, hence, high ozone concentration $(3.82 \mathrm{mg} / \mathrm{min})$ and long processing time $(4 \mathrm{~h})$ were used.

\subsection{HPLC}

Chromatographic analysis of the lipophilic fraction obtained from the pericarp and placenta of pepper fruits clearly showed their different chemical compositions (Figures 3 and 4 ). In the extracts of the pericarp, eight compounds were found, whose retention times were in the range of 5-25 min (Figure 3). In the placental extracts, the presence of other compounds was noticed, whose retention times were between 30 and $40 \mathrm{~min}$ (Figure 4). The obtained results confirm the fact that different anatomical parts of pepper fruits contain different compounds, despite their immediate vicinity. 
Similarly, in the fraction that showed medium lipophilicity, qualitative and quantitative differences were noted between the pericarp and placental extracts obtained from several pepper varieties [19,21].

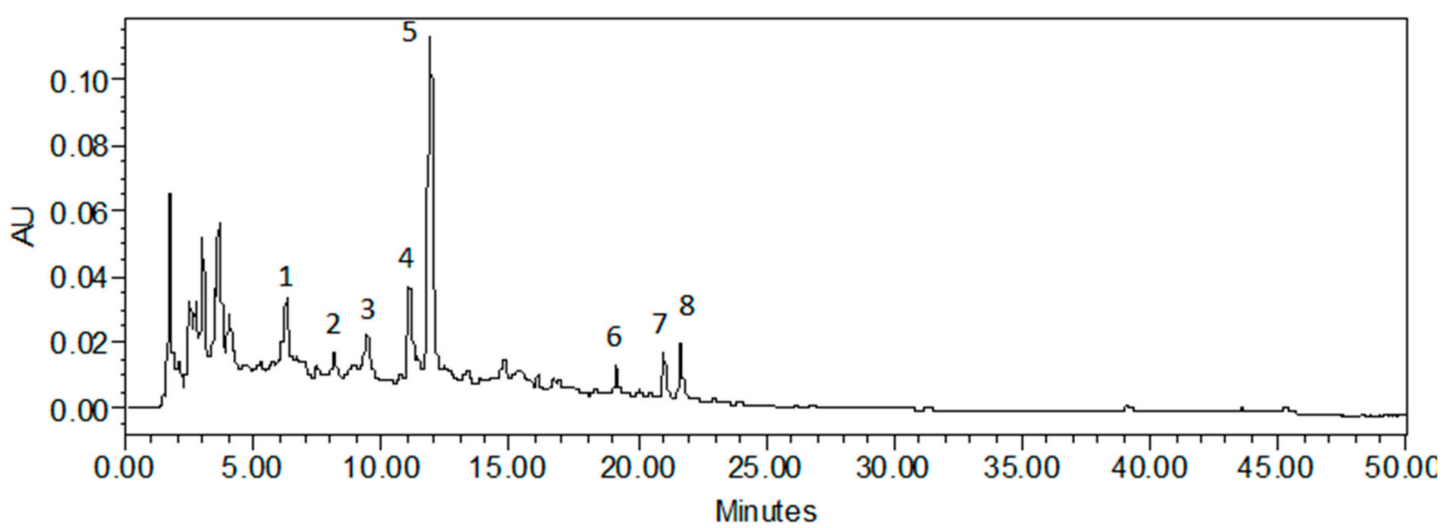

Figure 3. Chromatogram of the $70 \%$ aqueous methanol fraction extracted from pericarp of control pepper fruit.

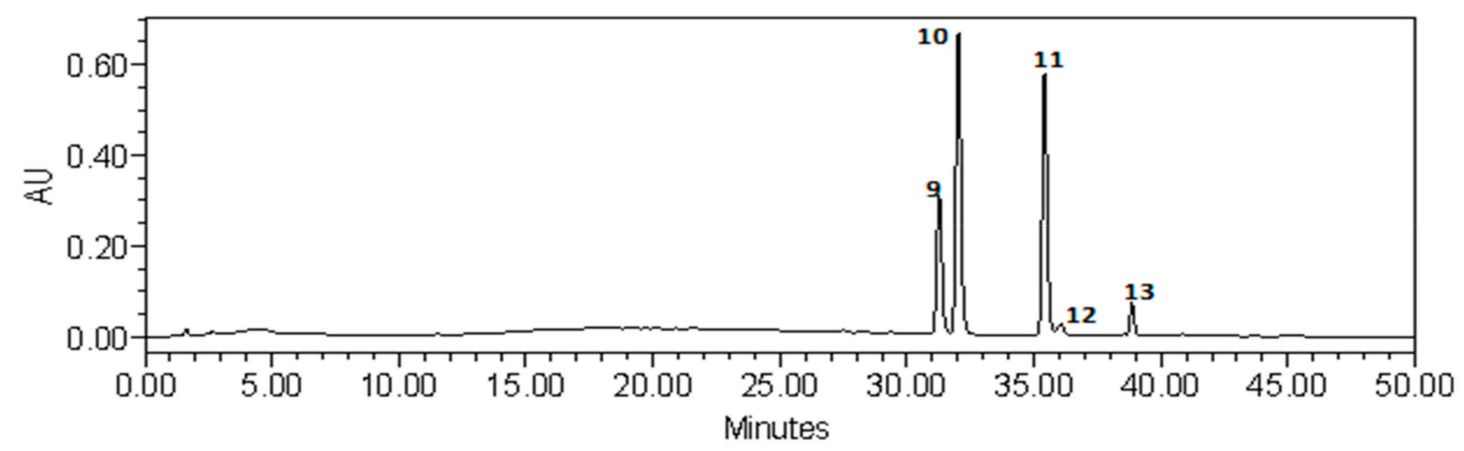

Figure 4. Chromatogram of the $70 \%$ aqueous methanol fraction extracted from placenta of control pepper fruit.

For a quantitative HPLC analysis, the standard curve of quercetin 3-O-rhamnoside was used, since the same compound was used for the quantitative estimation of unidentified components present in $40 \%$ fraction [19]. The effect of ozonization on the content of secondary metabolites in the pericarp and placenta of pepper fruits was investigated in this study, and the results showed a slight increase in the level of these compounds when subjected to ozone treatment for $1 \mathrm{~h}$, while ozonation for $3 \mathrm{~h}$ resulted in the accumulation of the analyzed compounds, whose concentration was almost doubled in pericarp and six-fold in placenta of pepper fruits (Table 1). The results obtained by chromatographic analysis were consistent with those obtained by spectrophotometric methods (Figure 1, Table 1). Treatment of pericarps with ozone for $1 \mathrm{~h}$ caused a reduction in the contents of these compounds after 20 days of ozonation (T20), while their concentration was almost doubled in pericarps treated for $3 \mathrm{~h}$. It is evident from the above findings that the lower dose of ozone probably causes the degradation of antioxidants under the influence of oxidative stress, while higher intensity of the stress factor stimulates the plant to synthesize greater amounts of compounds that act as substrates for the synthesis of antioxidants. This outcome is particularly evident in placental extracts ozonated for $3 \mathrm{~h}$, where the concentration of test compounds was more than five-fold higher in comparison with the control fruits on 10th day after ozonation (Table 1). To date, there have been no studies in the literature that have reported about changes in the concentration of lipophilic compounds following ozone treatment and the effect of storage on the content of these compounds in pepper fruits. In our earlier investigations, we noticed a positive effect of ozone on the level of quercetin derivatives 20 days after ozonation [19]. In the presented study, it was found that long-term storage of pepper fruits (up to 30 days from harvesting and ozonation) resulted in quantitative changes in the secondary metabolites; however, after the 20th 
day, the accumulation of these compounds was found to be the highest both in pericarp and placenta of pepper fruit (Table 1).

\subsection{PCA and Correlation Analysis}

The PCA showed the presence of numerous dependencies. As shown in Figure 5, the line representing compound no. 5 is the closest to the line indicating AA. Compounds (groups) have to be isolated, identified, and checked for AA. Moreover, compound no. 7 can be suspected to have a slightly different structure than the other compounds and seems to possess less antiradical activity. While in placenta (Figure 6), the presence of DPPH value line at a quite distant position indicates that phenolic compounds present in the placental region do not show high AA.

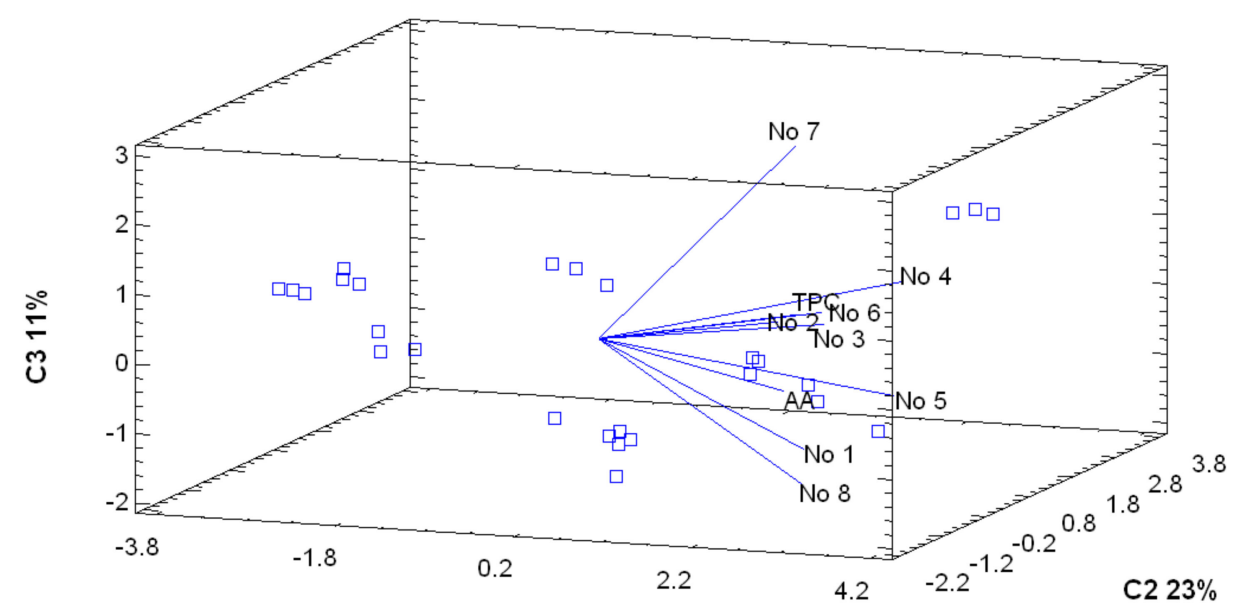

C1 $56 \%$

Figure 5. Principal components analysis of the tested parameters in pericarp. C1: Component $1 ; \mathrm{C} 2$ : Component 2; C3: Component 3; AA: Antiradical activity; TPC: Total phenolic content.

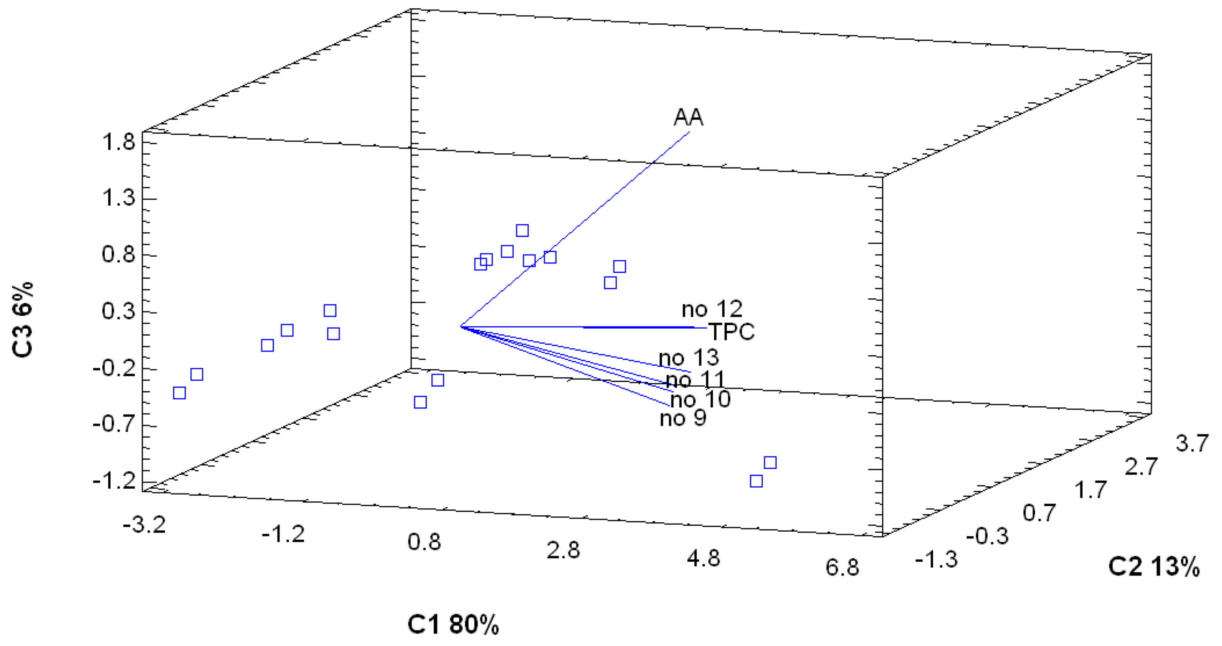

Figure 6. Principal components analysis of the tested parameters in placenta. 
Table 1. Content of phenolic compounds (quercetin-3-O-rhamnoside equivalent $\mathrm{mg} / 100 \mathrm{FM}$ ) in pericarp and placenta of pepper fruit as affected by ozonation and storage.

\begin{tabular}{|c|c|c|c|c|c|c|c|c|c|c|c|}
\hline & \multirow{3}{*}{ Peak no. ${ }^{1}$} & \multirow{3}{*}{$\begin{array}{l}\text { Retention } \\
\text { Time (min) }\end{array}$} & \multicolumn{3}{|c|}{ T10 } & \multicolumn{3}{|c|}{ T20 } & \multicolumn{3}{|c|}{ T30 } \\
\hline & & & \multicolumn{3}{|c|}{ Ozonation } & \multicolumn{3}{|c|}{ Ozonation } & \multicolumn{3}{|c|}{ Ozonation } \\
\hline & & & 0 & $1 \mathrm{~h}$ & $3 \mathrm{~h}$ & 0 & $1 \mathrm{~h}$ & $3 \mathrm{~h}$ & 0 & $1 \mathrm{~h}$ & $3 \mathrm{~h}$ \\
\hline \multirow{9}{*}{ Pericarp } & 1 & 6.2 & $0.527^{c *} \pm 0.010$ & $0.425^{\mathrm{d}} \pm 0.009$ & $0.709^{a b} \pm 0.053$ & $0.640^{b} \pm 0.16$ & $0.650^{\mathrm{ab}} \pm 0.011$ & $0.704^{\mathrm{ab}} \pm 0.011$ & $0.785^{a} \pm 0.024$ & $0.538^{c} \pm 0.015$ & $0.716^{a} \pm 0.067$ \\
\hline & 2 & 8.1 & $0.276^{c} \pm 0.012$ & $0.602^{b} \pm 0.054$ & $0.775^{a} \pm 0.069$ & $0.280^{c} \pm 0.013$ & $0.229^{c} \pm 0.024$ & $0.581^{b} \pm 0.006$ & $0.245^{c} \pm 0.019$ & $0.132^{d} \pm 0.003$ & $0.206^{c} \pm 0.016$ \\
\hline & 3 & 9.4 & $0.384^{\mathrm{d}} \pm 0.015$ & $0.273^{\mathrm{e}} \pm 0.030$ & $0.520^{c} \pm 0.008$ & $0.786^{a} \pm 0.021$ & $0.520^{c} \pm 0.013$ & $0.874^{a} \pm 0.010$ & $0.709^{a b} \pm 0.060$ & $0.597^{c} \pm 0.039$ & $0.569^{c} \pm 0.033$ \\
\hline & 4 & 11.1 & $0.411^{\mathrm{de}} \pm 0.001$ & $0.464^{\mathrm{de}} \pm 0.014$ & $1.071^{b} \pm 0.046$ & $1.107^{b} \pm 0.070$ & $0.840^{b c} \pm 0.045$ & $1.548^{a} \pm 0.012$ & $0.944^{b} \pm 0.066$ & $0.475^{\mathrm{d}} \pm 0.017$ & $0.648^{d} \pm 0.018$ \\
\hline & 5 & 11.9 & $1.269^{c} \pm 0.089$ & $1.370 \mathrm{bc} \pm 0.005$ & $3.374^{a} \pm 0.084$ & $3.360^{a} \pm 0.082$ & $1.943^{\mathrm{b}} \pm 0.108$ & $3.130^{\mathrm{a}} \pm 0.241$ & $2.455^{b} \pm 0.187$ & $1.625^{b c} \pm 0.073$ & $2.196^{b} \pm 0.089$ \\
\hline & 6 & 19.5 & $0.177^{c} \pm 0.010$ & $0.312^{b} \pm 0.009$ & $0.478^{a} \pm 0.015$ & $0.273^{b} \pm 0.009$ & $0.262^{b} \pm 0.018$ & $0.330^{\mathrm{b}} \pm 0.022$ & $0.157^{c} \pm 0.006$ & $0.059^{d} \pm 0.003$ & $0.163^{c} \pm 0.014$ \\
\hline & 7 & 21,0 & $0.305^{c} \pm 0.021$ & $0.257^{c} \pm 0.022$ & $0.562^{c} \pm 0.024$ & $0.611^{c} \pm 0.044$ & $2.375^{b} \pm 0.104$ & $4.313^{\mathrm{a}} \pm 0.050$ & $0.257^{c} \pm 0.021$ & $0.343^{c} \pm 0.003$ & $0.409^{c} \pm 0.038$ \\
\hline & 8 & 21.7 & $0.170 \mathrm{~d} \pm 0.011$ & $0.225 \mathrm{~d} \pm 0.023$ & $0.571 \mathrm{ab} \pm 0.039$ & $0.496^{b} \pm 0.022$ & $0.404^{c} \pm 0.024$ & $0.592^{a} \pm 0.010$ & $0.563 \mathrm{ab} \pm 0.014$ & $0.407^{c} \pm 0.027$ & $0.654^{a} \pm 0.036$ \\
\hline & \multicolumn{2}{|c|}{ Summary } & 3.519 & 3.928 & 8.06 & 7.553 & 7.223 & 12.072 & 6.115 & 4.176 & 5.561 \\
\hline \multirow{6}{*}{ Placenta } & 9 & 31.2 & $0.529^{c} \pm 0.03$ & $0.633^{b c} \pm 0.100$ & $3.506^{\mathrm{a}} \pm 0.267$ & $1.511^{\mathrm{b}} \pm 0.079$ & $1.253^{b} \pm 0.052$ & $1.099^{b} \pm 0.006$ & $0.444^{c} \pm 0.038$ & $0.236^{c} \pm 0.013$ & $1.240^{\mathrm{b}} \pm 0.034$ \\
\hline & 10 & 31.9 & $1.571^{c} \pm 0.102$ & $2.101 \mathrm{bc} \pm 0.052$ & $7.536^{a} \pm 0.044$ & $3.803^{b} \pm 0.059$ & $2.751^{\mathrm{b}} \pm 0.083$ & $3.057^{b} \pm 0.079$ & $1.107^{c} \pm 0.095$ & $0.627^{c} \pm 0.049$ & $3.211^{b} \pm 0.100$ \\
\hline & 11 & 35.4 & $1.003^{c} \pm 0.079$ & $1.660^{c} \pm 0.075$ & $6.500^{a} \pm 0.104$ & $3.400^{b} \pm 0.093$ & $2.116^{b c} \pm 0.113$ & $2.621^{b} \pm 0.202$ & $0.750^{\mathrm{cd}} \pm 0.014$ & $0.547^{\mathrm{cd}} \pm 0.041$ & $2.779^{b} \pm 0.101$ \\
\hline & 12 & 36.0 & $0.074^{\mathrm{cd}} \pm 0.010$ & $0.122^{c} \pm 0.019$ & $0.435^{a} \pm 0.014$ & $0.314^{b} \pm 0.028$ & $0.176^{c} \pm 0.013$ & $0.265^{b} \pm 0.015$ & $0.068^{\mathrm{cd}} \pm 0.007$ & $0.033^{\mathrm{d}} \pm 0.005$ & $0.186^{c} \pm 0.017$ \\
\hline & 13 & 38.8 & $0.131^{\mathrm{c}} \pm 0.006$ & $0.169^{c} \pm 0.007$ & $0.718^{a} \pm 0.008$ & $0.375^{b} \pm 0.020$ & $0.287^{b c} \pm 0.015$ & $0.394^{b} \pm 0.020$ & $0.122^{\mathrm{c}} \pm 0.009$ & $0.066^{\mathrm{c}} \pm 0.009$ & $0.279 b c \pm 0.026$ \\
\hline & \multicolumn{2}{|c|}{ Summary } & 3.308 & 4.685 & 18.695 & 9.403 & 6.583 & 7.436 & 2.491 & 1.509 & 7.695 \\
\hline
\end{tabular}

Notes: ${ }^{1}$ Peak numbers are the same as given in Figures 1 and $2 .{ }^{*}$ The data are expressed as the mean $(n=3) \pm$ SD; for each peak, values not sharing the same letter within the same row were significantly different at $p<0.05$. 
The Pearson's correlation analysis of the ozonation time and other tested parameters indicates numerous correlations (Table 2). The ozonation process particularly affected the placental region after 10 days of storage (T10). All the tested parameters were positively correlated with the duration of ozone treatment. Interestingly, after 20 days of storage, correlations were found to be reversed, and after 30 days (T30) they were again positive. The results for the pericarp region were slightly different. Some of the compounds showed high positive correlation with the duration of the ozonation process after 10 days of storage, while some showed after 10 days (at T20) and others after 30 days. A positive correlation was observed only for compound 7 in all the examined time periods. There was a negative linear relationship between ozonation and compound 3 at T30. The favorable influence of ozonation and antioxidative activity was only observed at T10 and T30, but not at T20. Thus, it can be concluded that ozonation causes immediate effects which seem to be sustained for a longer period of time.

Table 2. Pearson's correlation analysis of ozonation time and other tested parameters.

\begin{tabular}{|c|c|c|c|}
\hline Parameter & T10 & T20 & T30 \\
\hline \multicolumn{4}{|c|}{ Pericarp } \\
\hline 1 & 0.6308 & 0.9255 & -0.2723 \\
\hline 2 & 0.9848 & 0.7904 & -0.3420 \\
\hline 3 & 0.5498 & 0.2396 & -0.9449 \\
\hline 4 & 0.8997 & 0.6167 & -0.6241 \\
\hline 5 & 0.8864 & -0.1512 & -0.3046 \\
\hline 6 & 0.9983 & 0.7785 & 0.0585 \\
\hline 7 & 0.7826 & 0.9996 & 0.9973 \\
\hline 8 & 0.9221 & 0.5141 & 0.3656 \\
\hline HPLC sum & 0.9037 & 0.8339 & -0.2772 \\
\hline$\% A A$ & 0.8009 & 0.1132 & 0.7551 \\
\hline TPC & 0.8094 & -0.0173 & 0.9556 \\
\hline \multicolumn{4}{|c|}{ Placenta } \\
\hline 9 & 0.9002 & -0.9895 & 0.7508 \\
\hline 10 & 0.9034 & -0.6890 & 0.7653 \\
\hline 11 & 0.9155 & -0.6026 & 0.8219 \\
\hline 12 & 0.9209 & -0.3485 & 0.7375 \\
\hline 13 & 0.8932 & 0.1704 & 0.7131 \\
\hline HPLC sum & 0.9072 & -0.6799 & 0.7827 \\
\hline$\% A A$ & 0.9463 & -0.5770 & 0.7580 \\
\hline TPC & 0.9373 & -0.5906 & -0.5051 \\
\hline
\end{tabular}

\section{Conclusions}

Exposure of fruits to higher doses of ozone $(3 \mathrm{~h})$ induces the elicitation effect and increases the AA of the aqueous methanolic (70\%) fraction of pepper extract. The concentration and activity of secondary metabolites were found to be variable during storage, with the highest values recorded on the 20th day after harvest, both in control and ozonated fruits, regardless of the ozone dosage used. Ozonation for a period of $3 \mathrm{~h}$, but not $1 \mathrm{~h}$, showed a positive effect on the phenolic composition and antioxidant activity during prolonged storage of pepper fruits. Three hours of ozonation seems to be the appropriate exposure time to increase the persistence of pepper fruits during storage.

Author Contributions: Conceptualization: M.S.-K. and M.M.; Methodology: M.M.; Formal Analysis: M.S.-K. and B.C.; Investigation: M.S.-K. and B.C.; Data Curation: M.M.; Original Draft Preparation: M.S.-K. and M.M.; Review and Editing: M.S.-K. and M.M.; Supervision: B.C.

Funding: This research was funded by the program of the Minister of Science and Higher Education under the name "Regional Initiative of Excellence" in 2019-2022, project number 029/RID/2018/19, funding amount 11927 330.00 PLN. 
Conflicts of Interest: The authors declare no conflicts of interest. The funders had no role in the design of the study; in the collection, analyses, or interpretation of data; in the writing of the manuscript; or in the decision to publish the results.

\section{References}

1. Gutiérrez, D.R.; Chaves, A.R.; Rodríguez, S.C. UV-C and ozone treatment influences on the antioxidant capacity and antioxidant system of minimally processed rocket (Eruca sativa Mill.). Postharvest Biol. Technol. 2018, 138, 107-113. [CrossRef]

2. Alehosseini, A.; Ghorani, B.; Sarabi-Jamab, M.; Tucker, N. Principles of electrospraying: A new approach in protection of bioactive compounds in foods. Crit. Rev. Food Sci. Nutr. 2018, 58, 2346-2363. [CrossRef]

3. Jung, J.; Zhao, Y. Chapter 18-Antimicrobial Packaging for Fresh and Minimally Processed Fruits and Vegetables. In Antimicrobial Food Packaging; Academic Press: Cambridge, MA, USA, 2016; pp. 243-256.

4. Ahn-Jarvis, J.H.; Parihar, A.; Dose, A.I. Dietary Flavonoids for Immunoregulation and Cancer: Food Design for Targeting Disease. Antioxidants 2019, 8, 202. [CrossRef]

5. Luo, X.; Wang, R.; Wang, L.; Li, Y.; Bian, Y.; Chen, Z. Effect of ozone treatment on aflatoxin B1 and safety evaluation of ozonized corn. Food Control 2014, 37, 171-176. [CrossRef]

6. Botondi, R.; De Sanctis, F.; Moscatelli, N.; Vettraino, A.M.; Catelli, C.; Mencarelli, F. Ozone fumigation for safety and quality of wine grapes in postharvest dehydration. Food Chem. 2015, 188, 641-647. [CrossRef]

7. Trombete, F.M.; Freitas-Silva, O.; Saldanha, T.; Venâncio, A.; Fraga, M.E. Ozone against mycotoxins and pesticide residues in food: Current applications and perspectives. Int. Food Res. J. 2016, 23, 25-45.

8. Kırıs, S.; Velioglu, Y.S. Reduction in pesticide residue levels in olives by ozonated and tap water treatments and their transfer into olive oil. Food Addit. Contam. Part A 2015, 33, 128-136. [CrossRef]

9. De Souza, L.P.; Faroni, L.R.D.; Heleno, F.F. Ozone treatment for pesticide removal from carrots: Optimization by response surface methodology. Food Chem. 2018, 243, 435-441. [CrossRef]

10. Wang, S.; Wang, J.; Wang, T.; Li, C.; Wu, Z. Effects of ozone treatment on pesticide residues in food: A review. Int. J. Food Sci. Technol. 2019, 54, 301-312. [CrossRef]

11. Tzortzakis, N.; Borland, A.; Singleton, I.; Barnes, J. Impact of atmospheric ozone-enrichment on quality-related attributes of tomato fruit. Postharvest Biol. Technol. 2007, 45, 317-325. [CrossRef]

12. Alwi, N.A.; Ali, A. Dose-dependent Effect of Ozone Fumigation on Physiological Characteristics, Ascorbic Acid Content and Disease Development on Bell Pepper (Capsicum annuum L.) During Storage. Food Bioprocess Technol. 2015, 8, 558-566. [CrossRef]

13. Abdel-Wahhab, M.A.; Sehab, A.F.; Hassanien, F.R.; El-Nemr, S.E.; Amra, H.A.; Abdel-Alim, H.A. Efficacy of ozone to reduce fungal spoilage and aflatoxin contamination in peanuts. Int. J. Nuts Relat. Sci. 2011, 2, 1-14.

14. Ummat, V.; Singh, A.K.; Sidhu, G.K. Effect of aqueous ozone on quality and shelf life of shredded green bell pepper (Capsicum annuum). J. Food Process. Preserv. 2018, 42, 1-14. [CrossRef]

15. Maherani, B.; Harich, M.; Salmieri, S.; Lacroix, M. Antibacterial properties of combined non-thermal treatments based on bioactive edible coating, ozonation, and gamma irradiation on ready-to-eat frozen green peppers: Evaluation of their freshness and sensory qualities. Eur. Food Res. Technol. 2018, 245, 1095-1111. [CrossRef]

16. Kamber, U.; Gülbaz, G.; Aksu, P.; Doğan, A. Detoxification of Aflatoxin B1 in Red Pepper (Capsicum annuum L.) by Ozone Treatment and Its Effect on Microbiological and Sensory Quality. J. Food Process. Preserv. 2017, 41, e13102. [CrossRef]

17. Glowacz, M.; Colgan, R.; Rees, D. Influence of continuous exposure to gaseous ozone on the quality of red bell peppers, cucumbers and zucchini. Postharvest Biol. Technol. 2015, 99, 1-8. [CrossRef]

18. Glowacz, M.; Rees, D. Exposure to ozone reduces postharvest quality loss in red and green chilli peppers. Food Chem. 2016, 210, 305-310. [CrossRef]

19. Sachadyn-Król, M.; Materska, M.; Chilczuk, B.; Karaś, M.; Jakubczyk, A.; Perucka, I.; Jackowska, I. Ozone-induced changes in the content of bioactive compounds and enzyme activity during storage of pepper fruits. Food Chem. 2016, 211, 59-67. [CrossRef]

20. Mudric, S.Z.; Gašic, U.M.; Dramicanin, A.M.; Ciric, I.Z.; Milojkovic-Opsenica, D.M.; Popovic-Đordevic, J.B.; Momirovic, N.M.; Tešic, Z.L. The polyphenolics and carbohydrates as indicators of botanical and geographical origin of Serbian autochthonous clones of red spice paprika. Food Chem. 2017, 217, 705-715. [CrossRef] 
21. Materska, M. Bioactive phenolics of fresh and freeze-dried sweet and semi-spicy pepper fruits (Capsicum annuum L.). J. Funct. Foods 2014, 7, 269-277. [CrossRef]

22. Wahyuni, Y.; Ballester, A.R.; Sudarmonowati, E.; Bino, R.J.; Bovy, A.G. Metabolite biodiversity in pepper (Capsicum) fruits of thirty-two diverse accessions: Variation in health-related compounds and implications for breeding. Phytochemistry 2011, 72, 1358-1370. [CrossRef] [PubMed]

23. Zoriţa, D.; Florica, R.; Rugină, D.; Lucian, C.; Socaciu, C. HPLC/PDA-ESI/MS identification of phenolic acids, flavonol glycosides and antioxidant potential in blueberry, blackberry, raspberries and cranberries. J. Food Nutr. Res. 2014, 2, 781-785.

24. Singleton, V.L.; Rossi, J.A. Colorimetry of total phenolics with phosphotungstic acid reagents. Am. J. Enol. Vitic. $1965,16,144-158$.

25. Burda, S.; Oleszek, W. Antioxidant and antiradical activities of flavonoids. J. Agric. Food Chem. 2001, 49, $2774-2779$. [CrossRef] [PubMed]

26. Pan, X.; Kadla, J.F.; Ehara, K.; Gilkes, N.; Saddler, J.N. Organosolv ethanol lignin from hybrid poplar as a radical scavenger: Relationship between lignin structure, extraction conditions, and antioxidant activity. J. Agric. Food Chem. 2006, 54, 5806-5813. [CrossRef] [PubMed]

27. Ralph, J.; Lundquist, K.; Brunow, G.; Lu, F.; Kim, H.; Schatz, P.F.; Marita, J.M.; Hatfield, R.D.; Ralph, S.A.; Christensen, J.H.; et al. Lignins: Natural polymers from oxidative coupling of 4-hydroxyphenyl-propanoids. Phytochem. Rev. 2004, 3, 29-60. [CrossRef]

28. Alothman, M.; Kaur, B.; Fazilah, A.; Bhat, R.; Karim, A.A. Ozone- induced changes of antioxidant capacity of fresh-cut tropical fruits. Innov. Food Sci. Emerg. Technol. 2010, 11, 666-671. [CrossRef]

29. Ong, M.K.; Ali, A.; Alderson, P.G.; Forney, C.F. Effect of different concentrations of ozone on physiological changes associated to gas exchange, fruit ripening, fruit surface quality and defence-related enzymes levels in papaya fruit during ambient storage. Sci. Hortic. 2014, 179, 163-169. [CrossRef]

30. Rodoni, L.; Casadei, N.; Concellón, A.; Chaves Alicia, A.R.; Vicente, A.R. Effect of short-term ozone treatments on tomato (Solanum lycopersicum L.) fruit quality and cell wall degradation. J. Agric. Food Chem. 2010, 58, 594-599.

31. Brodowska, A.J.; Śmigielski, K.; Nowak, A.; Czyżowska, A.; Otlewska, A. The Impact of Ozone Treatment in Dynamic Bed Parameters on Changes in Biologically Active Substances of Juniper Berries. PLoS ONE 2015, 10, e0144855. [CrossRef]

32. Onopiuk, A.; Półtorak, A.; Moczkowska, M.; Szpicer, A.; Wierzbicka, A. The impact of ozone on health-promoting, microbiological, and colour properties of Rubus ideaus raspberries. CyTA J. Food 2017, 15, 563-573. [CrossRef]

33. Ruiz-Garcia, Y.; Romero-Cascales, I.; Gil-Munoz, R.; Fernandez-Fernandez, J.I.; LopezRoca, J.; Gomez-Plaza, E. Improving grape phenolic content and wine chromatic characteristics through the use of two different elicitors: Methyl jasmonate versus benzothiadiazole. J. Agric. Food Chem. 2012, 60, 1283-1290. [CrossRef] [PubMed]

34. Wang, L.; Ma, L.; Xi, H.; Duan, W.; Wang, J.; Li, S. Individual and combined effects of CaCl2 and UV-C on the biosynthesis of resveratrols in grape leaves and berry skins. J. Agric. Food Chem. 2013, 61, 7135-7141. [CrossRef] [PubMed]

35. Portu, J.; Lopez-Alfaro, I.; Gomez-Alonso, S.; Lopez, R.; Garde-Cerdan, T. Changes on grape phenolic composition induced by grapevine foliar applications of phenylalanine and urea. Food Chem. 2015, 180, 171-180. [CrossRef] [PubMed]

36. Zou, Y.; Yang, M.; Zhang, G.; He, H.; Yang, T. Antioxidant activities and phenolic compositions of wheat germ as affected by the roasting process. J. Am. Oil Chem. Soc. 2015, 92, 1303-1312. [CrossRef]

37. Paissoni, M.A.; Segade, S.R.; Giacosa, S.; Torchio, F.; Cravero, F.; Englezos, V.; Rantsiou, K.; Carboni, C.; Gerbi, V.; Teissedre, P.L.; et al. Impact of post-harvest ozone treatments on the skin phenolic extractability of red winegrapes cv Barbera and Nebbiolo (Vitis vinifera L.). Food Res. Int. 2017, 98, 68-78. [CrossRef] [PubMed]

38. De Souza, J.A.; Angolini, C.F.; Eberlin, M.N.; de Aguiar, C.L. Criegee mechanism as a safe pathway of color reduction in sugarcane juice by ozonation. Food Chem. 2017, 225, 181-187. [CrossRef] [PubMed]

(C) 2019 by the authors. Licensee MDPI, Basel, Switzerland. This article is an open access article distributed under the terms and conditions of the Creative Commons Attribution (CC BY) license (http://creativecommons.org/licenses/by/4.0/). 